\title{
Pott's Disease: A Diagnosis that Should Never be Forgotten
}

\author{
Rosa Carvalho*, Luís Dias, Vânia Gomes, Céu Rodrigues and Carlos Capela \\ Internal Medicine Service, Hospital de Braga, Portugal
}

Submission: September 21, 2018; Published: October 12, 2018

*Corresponding author: Rosa Carvalho, Internal Medicine Service, Hospital de Braga, Braga, Portugal, Email: rosa.macedo.carvalho@gmail.com

\begin{abstract}
Pott's disease (PD) or spinal tuberculosis is a rare condition which accounts for less than $1 \%$ of total tuberculosis (TB) cases and despite a progressive decline in the number of the cases of tuberculosis all over the world, still remains a significant cause of morbidity in this patients. We present the clinical case of a 79 year-old female that was admitted to our Internal Medicine Service to study a fever of unknown origin. Despite the extensive study realized, no focalization on infectious, neoplastic, inflammatory or lymphoproliferative etiologies was found and the patient was discharged for maintenance the study in external consult. 3 weeks later and with persistent complaints of low back pain, a CT scan of the column showed showed extensive process of spondylodiscitis with vertebral abscess. An abscess puncture was performed and microbiology cultures confirmed the diagnosis of TB. This case highligths the importance of early recognition of Pott's disease, a rare and serious manifestation of TB infection,and its recognition helps to prevent permanent neurological sequelae and other phisycal damage.
\end{abstract}

Keywords: Infectious; Neoplastic; Inflammatory; Lymphoproliferative etiologies; Tuberculosis;Musculoskeletal infection

\section{Introduction}

Tuberculosis of the bones and joints remains rare, accounting for only about 1 to $3 \%$ of all cases of tuberculosis with similar incidence time trends. Despite a progressive decline in the number of cases of tuberculosis (TB) in industrialized countries, TB still remains a significant cause of musculoskeletal infection in many parts of the world. In 2014, among all 6 million notified cases of tuberculosis (TB), 0.8 million (14\%) were new cases of extrapulmonary tuberculosis [1]. The skeletal system is the most common extrapulmonary site of involvement. It may be involved as a result of hematogenous spread from a primary focus, which is usually the lung,13 and less commonly from lymph nodes, kidneys, or any other viscera. Tuberculous spondylitis, also called Pott disease, accounts for $1-5 \%$ of TB cases and represents about $50 \%$ of all bone and joint TB [2].

Musculoskeletal TB equally affects men and women, with no significant differences by country of origin, race, or ethnicity. Skeletal TB is characteristically insidious in onset and indolent in manifestation, with no alarming general clinical features. Constitutional symptoms include low grade fever, night sweats, weight loss, anorexia, and malaise. Skeletal involvement is associated with localized warmth, swelling, and tenderness [3]. Pain is the most common presenting manifestation. However, the limited symptoms and absence of specific radiological changes early in the course of the infection often result in diagnostic delays. Computed tomography (CT) and magnetic resonance imaging
(MRI) are valuable diagnostic tools. Confirmation of the diagnosis is obtained by identification of the tubercle bacillus in respiratory specimens and/or in samples obtained by abscess aspiration or bone biopsy [4].

\section{Case Description}

A 79-year-old patient with a history of osteoarticular disease and cerebrovascular disease was admitted to our Service for the studyfever of unknown origin. She complained of fever, low grade, with a few weeks of evolution, but without associated low back pain, hypersudoresis, weight loss, asthenia or anorexia. Initial physical examination was unremarkable. Laboratory results showed inflammation, but extensive testing for bacteriological and viral serology was negative. Throughout the hospitalization the patient only occasionally referred to low back pain, related to said antecedent of compressive fracture ofL1 and labeled L5-S1 listesis and she only had one peak of low grade fever $\left(37,3^{\circ} \mathrm{C}\right)$. In what concerns of the rest of the study, CT scan of the throrax, abdomen and pelvis without alterations, colonoscopy and high endoscopy unremarkable. She was discharged to mantaining study in external consult and returned 3 weeks later with complaints with low back pain and persisting low grade fever. A CT scan of the column was request, and showed extensive process of spondylodiscitis with vertebral abscess. An abscess puncture was performed and microbiology cultures send to the laboratory. Magnetic ressonance of the column was also performed and 


\section{Juniper Online Journal of Case Studies}

described an extensive infectious process, with starting point in spondylodiscitis, involving the bodies L3, L4 and L5 vertebrae. The infectious process has intracanal expression, with an emphasis on anterior epidural predominance and collection from L3 to L5-S1, which involves the corresponding nerve roots in its path and in the lateral recesses. There is a marked prior list of L5 on S1 grade II of Meyerding due to degenerative changes. The corresponding conjugation holes are not large. Change of sign of parts vertebral, suggestive of osteomyelitis from L3 to L5, with components abcedados associated with pre-vertebral, with a maximum thickness of $7.2 \mathrm{~mm}$, to the left, and massive collection abcedada with path along the muscle psoas, with $12 \mathrm{~cm}$ of extension, to the right (Figure 1). Microbiology of pus identified the presence of mycobacterium tuberculosis and the patient initiated targeted therapy with isoniazid, rifampicin, pyrazinamide and ethambutol.

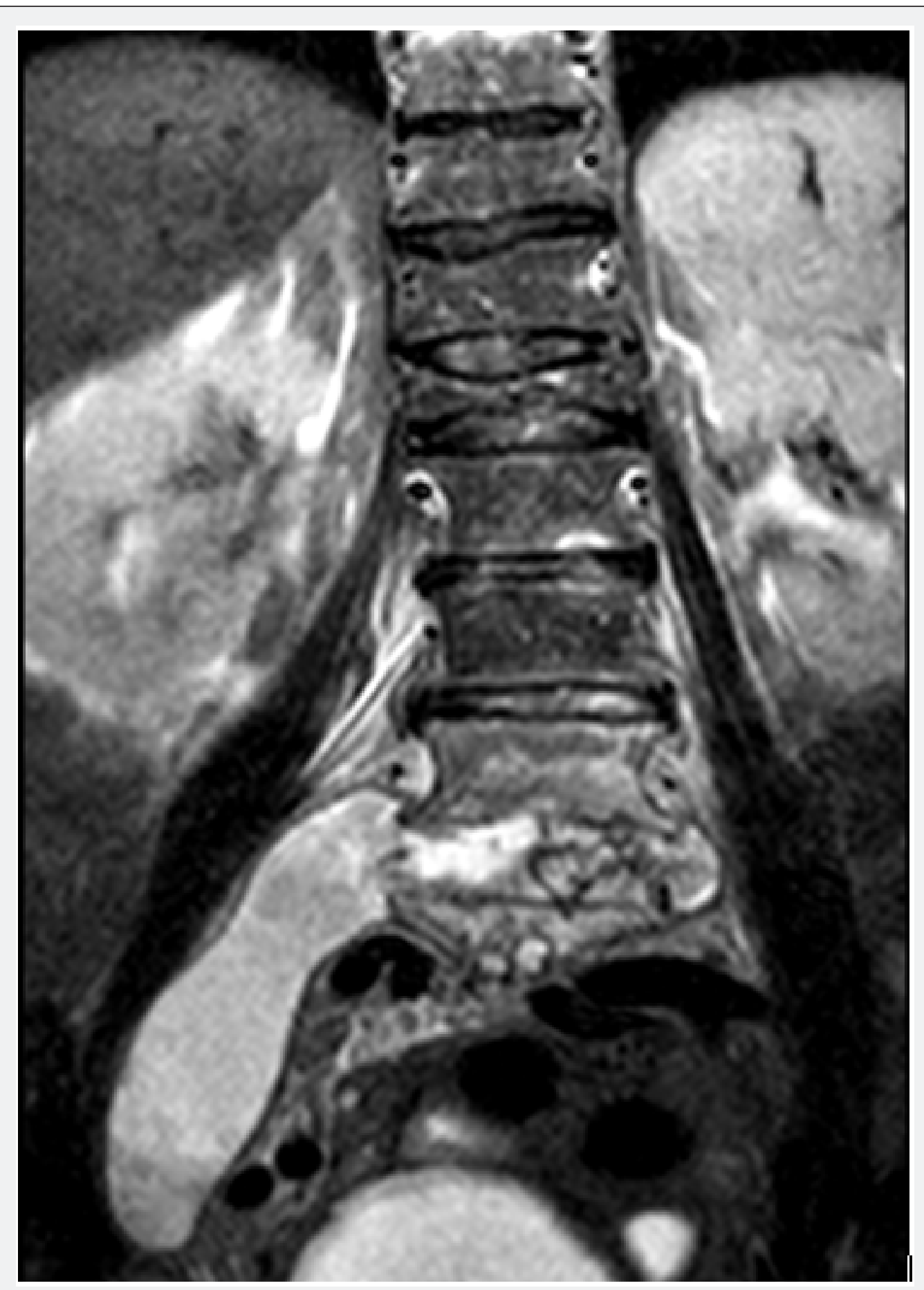

Figure 1 


\section{Discussion and Conclusion}

Spinal tuberculosis (Pott's disease) predominantly affects the thoracic spine and is often diagnosed late. The treatment of spinal tuberculosis usually relies on non-surgical means, namely, the administration of four anti-tuberculosis drugs and bracing [5]. Two situations may require surgical treatment: loss of sagittal alignment of the spine due to extensive osteolysis and spread of an abscess into the para-spinal tissues and spinal canal [1]. The goal of tuberculous spondylitis treatment is not only to eradicate infection but also to treat and prevent neurological complications and spinal deformities. Pharmacological treatment should be initiated as soon as the diagnosis is confrmed, with 2 months of HRZE (intensive phase) followed by 4 to 7 months of HR (continuation phase) but the duration of treatment remains controversial. Due to dificulties in assessing response and risk of relapse, most experts recommend 9 to 12 months of treatment, and in situations of slow radiological resolution as case 2, 12 to 24 months of treatment should be considered[6]. This case highligths the importance of early recognition of Pott's disease, a rare and serious manifestation of TB infection, to prevent permanente neurological sequelae.

\section{References}

1. Varatharajah S, Charles YP, Buy X, Walter A, Steib JP (2014) Update on the surgical management of Pott's disease. Orthop Traumatol Surg Res 100(2): 229-235.

2. Walls T, Shingadia D (2007) The epidemiology of tuberculosis in Europe. Arch Dis Child 92(8): 726-729.

3. Golden MP, Raphael S, Haven N (2005) Extrapulmonary Tuberculosis: An Overview 72(9): 3-11.

4. Cantwell LM, Perkins JC, Keyes DCV (2018) Pott's Disease in a Patient with Subtle Red Flags. J Emerg Med 54(3): e37-e40.

5. Garg RK, Somvanshi DS (2011) Spinal tuberculosis: A review. J Spinal Cord Med 34(5): 440-454.

6. Lacerda C, Linhas R, Duarte R (2017) Tuberculous Spondylitis: A Report of Different Clinical Scenarios and Literature Update. Case Reports in Medicine 2017(4165301): 4.

\section{Your next submission with Juniper Publishers will reach you the below assets}

- Quality Editorial service

- Swift Peer Review

- Reprints availability

- E-prints Service

- Manuscript Podcast for convenient understanding

- Global attainment for your research

- Manuscript accessibility in different formats

( Pdf, E-pub, Full Text, Audio)

- Unceasing customer service

Track the below URL for one-step submission https://juniperpublishers.com/online-submission.php 